\title{
Integration of ceritinib and bevacizumab as a promising treatment strategy for brain metastases from ALK mutation-position non-small cell lung cancer: a case report
}

Yinxue Xia ${ }^{1}$, Shuhe $\mathrm{Lu}^{1}$, Weixi Shen ${ }^{2}$, Tao Xin ${ }^{2}$, Chengjuan Fan², Chong Teng ${ }^{2}$, Xiaowei Song ${ }^{2}$, and Yanju $\mathrm{Lv}^{2}$

${ }^{1}$ Harbin Medical University

${ }^{2}$ Second Affiliated Hospital of Harbin Medical University

March 25, 2021

\begin{abstract}
Ceritinib shows efficacy in ALK+ NSCLC patients with BM. However, the disease will inevitably progress over time due to acquired resistance. We now report a case with BM from advanced lung adenocarcinoma with ALK mutations who exhibited a surprising and long-term response to treatment of ceritinib combined with bevacizumab.
\end{abstract}

\section{Hosted file}

Manuscript.pdf available at https://authorea.com/users/404053/articles/515368-integrationof-ceritinib-and-bevacizumab-as-a-promising-treatment-strategy-for-brain-metastasesfrom-alk-mutation-position-non-small-cell-lung-cancer-a-case-report

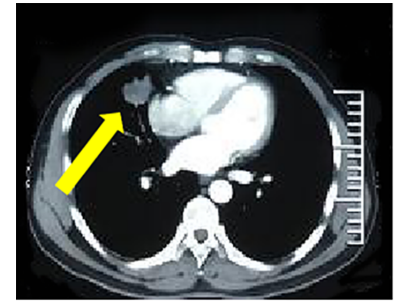

Figure 1

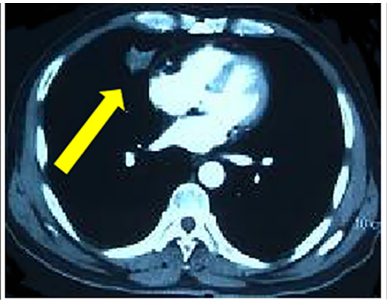

Figure 2

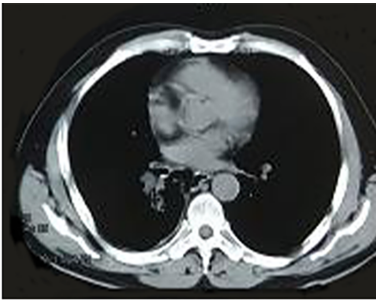

Figure 3 


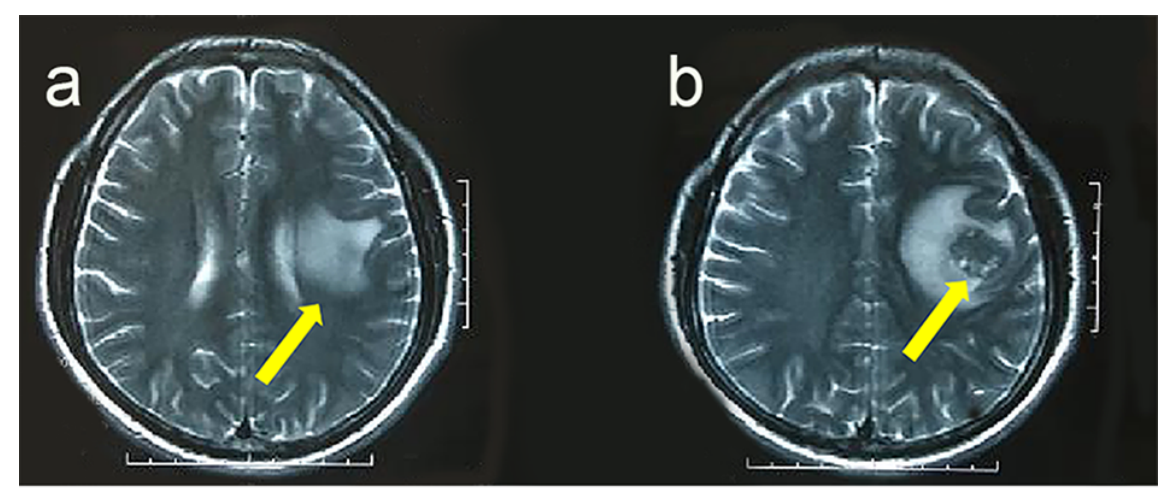

Figure 4(a,b)

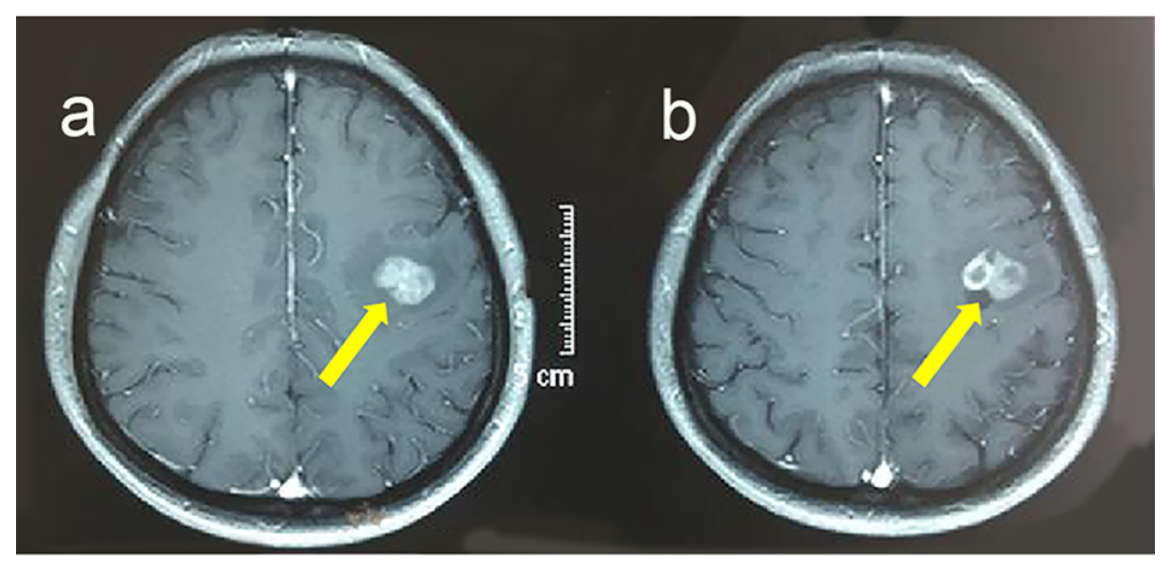

Figure 5(a,b)

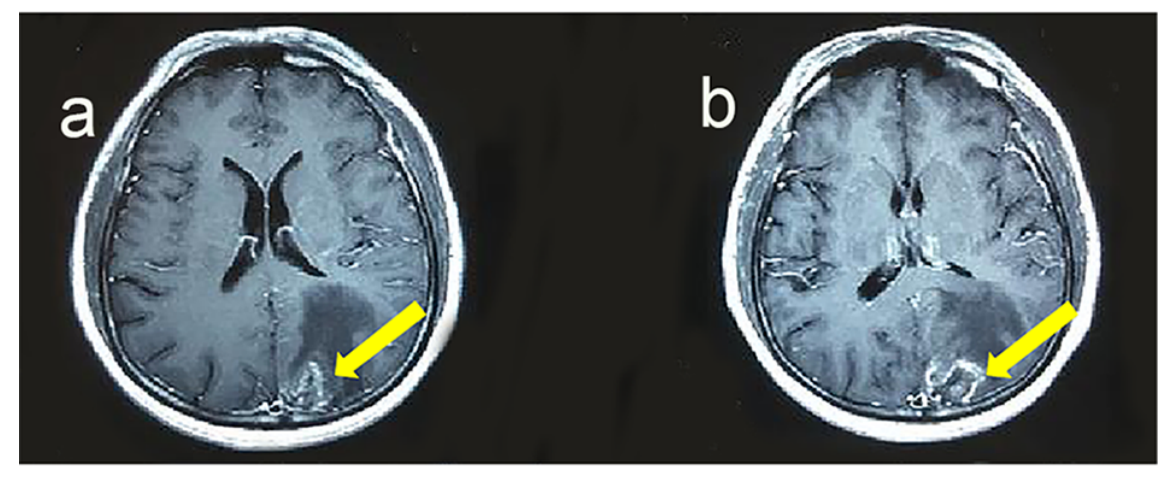

Figure 6(a,b) 

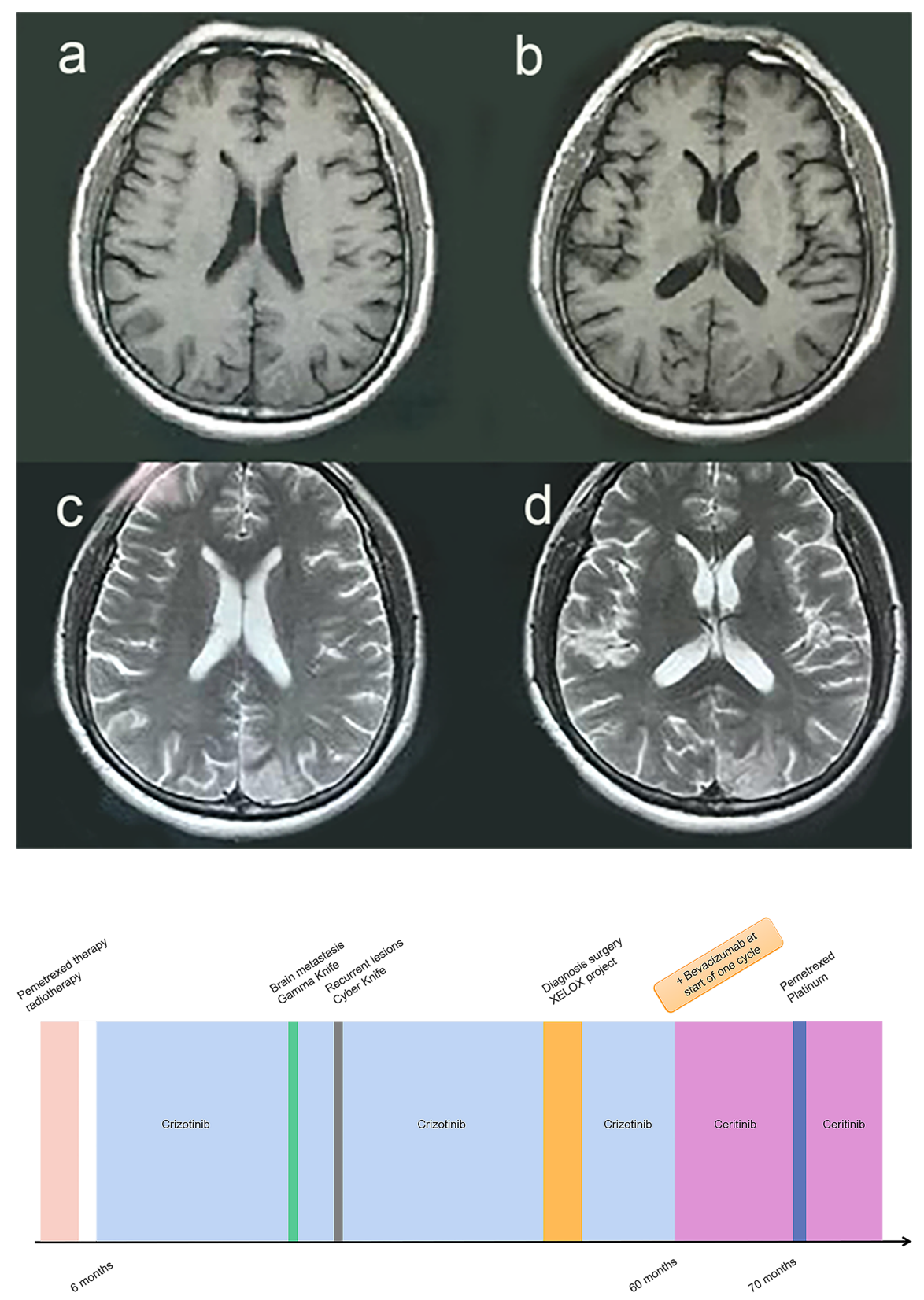